\title{
CLIMA, TROPICALIDADE E SAÚDE: UMA PERSPECTIVA A PARTIR DA INTENSIFICAÇÃO DO AQUECIMENTO GLOBAL.
}

\author{
Francisco Mendonça ${ }^{1}$
}

\begin{abstract}
RESUMO
A climatologia, através da bioclimatologia humana, constitui um campo de estudos de interesse da saúde pública. Este interesse torna-se mais importante no atual contexto das mudanças climáticas globais, pois que a intensificação do aquecimento climático planetário é um fato aceito pela maior parte de cidadãos e cientistas de todo o mundo. Elas poderão causar consideráveis impactos na saúde de parcelas importantes da humanidade, todavia ocorrerão de maneira bastante distinta na superfície da Terra. Na zona tropical as alterações serão bem menos expressivas que aquelas a se processarem nas médias e altas latitudes. Nos trópicos, acredita-se, as doenças transmissíveis e parasitárias encontrarão melhores condições para sua expansão, sendo que constituirão um elevado risco ante à vulnerabilidade da maioria da população. Doenças como a malaria e a dengue, dentre outras, poderão ter seus espaços ampliados em latitude e em altitude, envolvendo um numero bastante elevado de vitimados num futuro próximo.
\end{abstract}

Palavras chave: Clima, tropicalidade, aquecimento global, saúde.

\section{CLIMATE, TROPICALITY AND HEALTH: A PERSPECTIVE FROM THE GLOBAL WARMING INTENSIFICATION}

\begin{abstract}
The climatology, through the human bioclimatology, constitutes an interesting study field to the public health. This interest becomes more important in the current context of global climatic changes, therefore that the intensification of the planetary climatic heating is an accepted fact mostly of citizens and scientists of the whole world. They will be able to cause considerable impacts in the health of important parcels of the humanity; however they will occur in sufficiently distinct way in the surface of the Earth. In the tropical zone the alterations will be well less remarkable than those if to process in the mean and high latitudes. On the tropics, one gives credit, the transmissible and the parasitic illnesses will find better conditions for its expansion, being that they will constitute one high risk in regards of the vulnerability of the majority of the population. Illnesses as it the affection would malaria and dengue, amongst others, will be able to have its spaces extended in latitude and in altitude, involving one number sufficiently high of victims in a next future.
\end{abstract}

Keywords: Climate, tropicality, global warming, health.

1 Laboclima - Universidade Federal do Parana. ABClima - Presidente 2002-2004. 


\section{Introdução}

"The prospect that climate change and other environmental changes will affect population health poses radical challenges to scientists; fortunately, this has arisen at a time of growing interest among epidemiologists in studying and understanding the population-level influences on patterns of health disease. (...)".

Martens and McMichel (2002: 9)

Ainda que, em varios aspectos, a influência do clima sobre as atividades humanas tenha sido reduzida devido aos avanços da tecnologia, "the significance of weather has not diminished in modern society. (...)" (Reiter, 2001: 141). Mesmo considerando que o anacrônico determinismo climático esteja fora de discussão no quadro do debate atual, cuidados são necessários para não se buscar explicações que subestimem a influência da natureza nas atividades humanas e no bem estar da população. De toda maneira, a abordagem da relação entre a sociedade e a natureza, devido às profundas transformações produzidas por aquela sobre esta, demanda novas abordagens no presente. É, então, neste quadro de novos desafios ao conhecimento e à sua aplicação que o clima se coloca e se reforça como elemento de interesse científico-técnico e cultural e de grande importância para o equacionamento de determinados problemas sócio-ambientais.

De maneira geral os estudos da relação entre o clima e a saúde humana, objeto deste texto, são elaborados na perspectiva da influência daquele nesta. O clima desempenha tanto efeitos favoráveis quanto desfavoráveis à boa saúde, e a abordagem aqui esboçada volta-se à esta última, pois que "(...) I'action de l'environnement physique ne devient évidente que lorsque les éléments du milieu extérieur agissent en excès et déterminent un désordre pathologique; elle n'en est pas moins effective en tous lieux et toutes circonstances. (...)" (Besancenot, 2001: 9).

Desde os trabalhos de Hipocrates, na Grécia Clássica, até o momento presente, uma quantidade considerável de estudos voltados à analise da influência do clima sobre a saúde fisiológica e o comportamento dos homens foi desenvolvida. A grande maioria deles enfoca o efeito desempenhado pelas condições climáticas e meteorológicas sobre a incidência de determinadas doenças, pois o clima atua tanto sobre os agentes patogênicos (virus e bactérias, principalmente) e os vetores quanto diretamente sobre o corpo humano. Assim é que "a relação entre os dois meios, o do corpo e o do ambiente externo - atmosférico, constitui a base da bioclimatologia" (Lamarre et Pagney, 1999: 105).

Para Besancenot (1997: 87) a bioclimatologia humana tem por objetivo o estudo "dos efeitos diretos ou indiretos, irregulares, flutuantes ou cíclicos, do tempo que faz ou do clima sobre a saúde e a ocorrência de doenças, sendo entendido que o tempo age a curto prazo e o clima a médio e longo prazo". Este autor a concebe como subdividida em três campos principais, que são a climatofisiologia, a climatopatologia e a climatoterapia. Interessante também é a associação por ele estabelecida entre os riscos climatopatológicos (derivados de «climas fortemente agressivos ou de paroxismos climáticos particularmente violentos») e a vulnerabilidade humana aos mesmos (ligada à 
especificidades «de determinados indivíduos à fenômenos climáticos particulares») (Op Cit: 99).

A partir desta relação entre riscos e vulnerabilidades da saúde humana ao clima, Besancenot (1997: 100) avança a idéia de climatosensibilidade, através da qual evidencia a influência de determinadas condições climáticas sobre um certo numero de indivíduos no interior de um mesmo grupo. Assim, o risco climático não está diretamente relacionado a uma patologia claramente caracterizada, pois cada pessoa reage diferentemente, segundo uma série de elementos, à influência do clima sobre si. De toda maneira, os efeitos do clima no desenvolvimento de doenças humanas se fazem sentir mais acentuadamente na parcela da população que está mais diretamente à mercê de sua ação, ou seja, os mais pobres e de menor acesso aos recursos tecnológicos.

Desta maneira se observa, uma vez mais, que a concepção determinística da relação entre o clima e a saúde humana não atende aos objetivos dos estudos elaborados no presente. É também valido assinalar que estes estudos ultrapassam a longa e duradoura fase de busca de explicações para a referida relação e avançam para uma nova fase, na qual prevalecem a analise e a correlação, pois o clima é somente mais um fator a ser considerado no processo saúde-doença da população. Ele pode assumir importância capital num determinado processo, ou ser apenas fator coadjuvante de um outro.

Temperatura, pressão e umidade atmosféricas, e seus fenômenos derivados (calor, frio, ventos, chuva, neve, etc.), compõem o conjunto de elementos formadores do clima (Mendonça e Danni-Oliveira, 2005). Quando se desenvolve a abordagem da interação entre os mesmos e o organismo humano se retoma, indubitavelmente, um deles em particular ou a associação entre mais de um. O estudo reveste-se de um caráter, na maioria das vezes, multi e interdisciplinar, pois que evoca conhecimentos da meteorologia, da climatologia, da medicina, da epidemiologia, da estatística, dentre outras. Em estudos de determinadas problemáticas, como é o caso da saúde humana aqui enfocada, a abordagem a partir de um único campo disciplinar torna-se claramente insatisfatória e insuficiente quanto à compreensão e proposição de equacionamento para a mesma.

Um estudo sobre as interações entre as condições climáticas e as reações fisiológicas e comportamentais humanas evidencia uma considerável pluralidade de exemplos nos mais diferentes contextos, aspecto que reflete a importante diferenciação de biomas do mundo. Sorre (1984), analisando esta interação concebeu o conceito de "complexo patogênico", no qual evidenciou determinadas particularidades do mundo Tropical. Alguns aspectos da interação entre o clima e a saúde humana na zona inter-tropical do planeta foram enfocados em Mendonça (2004), e são aqui retomados e enriquecidos na perspectiva da discussão das repercussões da intensificação do aquecimento climático global.

\section{Aquecimento global e saúde: Um debate acirrado.}

Ao longo de sua evolução a atmosfera terrestre apresentou estágios bastante diferenciados quanto à sua composição química e física. Períodos quentes e úmidos se alternaram com quentes e secos, frios e úmidos e frios e secos, gerando condições climáticas bastante distintas daquelas observadas na 
atualidade. Todavia, foi somente após as ultimas grandes glaciações que se registraram na Terra condições favoráveis ao desenvolvimento da vida humana no planeta, fato este decorrente do aquecimento da atmosfera observado de meados para o final da Era Cenozóica (Holoceno). Estas evidências levam à constatação, primeira e necessária, de que a atmosfera terrestre não apresentou uma evolução linear e uniforme, ou seja, sua historia é marcada por alterações significativas e que contemplam também a intensificação das temperaturas na atualidade. Assim, parece necessário reafirmar, a intensificação do efeito-estufa planetário na Era Moderna não esta dissociada da própria dinâmica da natureza, ainda que ela evidencie impactos derivados das atividades humanas.

Períodos com condições térmicas mais elevadas que as atuais já ocorreram na Terra, todavia "currently, world climate is in a warming phase that began in the early decades of the eighteenth century. Temperatures, at least in the Northern Hemisphere, are now broadly similar to what they were during the Middle Ages, in the centuries before the Little Ice Age. Awareness of this warming has led to a new preoccupation: concern that human activities may be affecting the natural climatic regime, just as they are changing many other aspects of the environment. (...)" (Reiter, 2001: 141/142).

Embora se observe uma crença geral entre os cientistas da atmosfera de que o aquecimento global apresenta uma tendência de intensificação considerável neste século XXI, momento no qual as implicações sobre a saúde humana, dentre outros, se fará mais evidente, observa-se também afirmações que apontam a ocorrência do processo contrario, ou seja, do resfriamento da atmosfera. Dentre as argumentações que tomam esta perspectiva cita-se a interferência das cinzas e gases derivados das explosões vulcânicas no processo de radiação Sol-Terra-Espaço, bem como a ODP Oscilação Decadal do Pacífico (Mollion apud Mendonça, 2004).

Ainda que dissonantes no âmbito do discurso globalizado das mudanças climáticas atuais, parece prudente não desacreditar totalmente nas perspectivas que postulam o processo de resfriamento, embasadas que estão em princípios de lógica cientifica e técnica fiável. Estas concepções explicitam, por sua vez, tanto posições discordantes acerca da evolução da atmosfera terrestre e seus impactos sobre as atividades humanas, quanto deixam em evidência a característica especulativa da maioria dos prognósticos lançados acerca dos efeitos daquela sobre estes.

A posição aqui assumida, ainda que atenta aos argumentos relativos ao resfriamento da atmosfera terrestre, é partidária da concepção da intensificação do aquecimento climático global. Neste âmbito, e considerando que as principais mudanças climáticas globais (regionais e locais) ocorrerão de maneira mais evidente no século XXI, passando posteriormente a uma maior estabilidade (IPCC, 2005), importa aqui evidenciar alguns de seus impactos sobre a saúde humana, particularmente nas áreas tropicais como se verá a seguir.

Vários estudiosos têm construído e divulgado cenários derivados do impacto das mudanças globais sobre a saúde humana, sendo que poucos se contradizem quanto às perspectivas generalizantes. Cliff and Hagget (1995), ao argumentar sobre a importante transição epidemiológica relacionada ao expressivo crescimento populacional no século $\mathrm{XX}$, consideraram três temas 
como resultantes destas mudanças, quais sejam: a) os impactos do trabalho a grandes distâncias, b) as implicações geográficas do aquecimento global sobre as doenças, e c) os fatores relacionados às novas doenças (ou aparentemente novas). O segundo tema - e parte do terceiro - é de interesse direto da discussão elaborada neste texto, pois que as mudanças globais abrangem uma gama de temas bastante ampla e complexa, da qual o clima é um dos componentes. Neste sentido retoma-se aqui a contribuição de Besancenot (2001), por exemplo, que esquematizou, de maneira bastante didática, os impactos do aquecimento global sobre as condições de mortalidade e morbidade humana (Figura 1), evidenciando reflexos diretos e indiretos daquele nestas; retoma-se também a abordagem introdutória de Mendonça (2004) que atribuiu ênfase nas especificidades do mundo tropical.

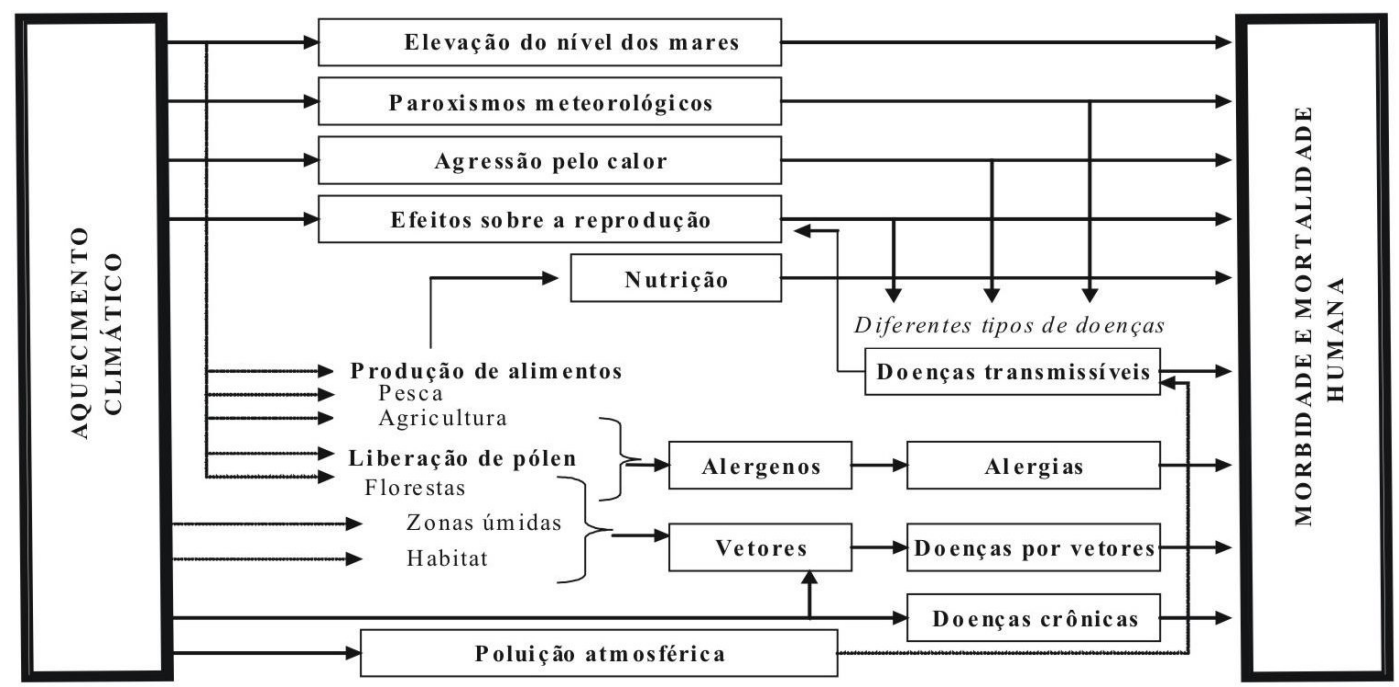

Figura 1. Aquecimento climático e saúde.

Fonte: Besancenot (2001).

Em relação aos impactos do aquecimento global sobre as condições de doença e de saúde da população, Besancenot (2001:121) considera que "La question est de savoir quelles seraient les conséquences sanitaires du phénomène. Certaines s'exerceraint directement sur lorganisme humain, tandis que d'autres se feraient sentir en façonnant des conditions écologiques plus ou moins favorables à la survie, à la multiplication et au développement de tel ou tel germe pathogène, ou encore de tel ou tel insecte vecteur de ce germe". Acrescenta ainda ele a necessidade da reflexão acerca da escala temporal de manifestação das mudanças climáticas ao dizer que (:123) "En fait, tout dépend de la brutalité avec laquelle s'opérerait le réchauffement. Une évolution lente, permettant une acclimatation progressive, n'aurait que peu de conséquences sanitaires néfastes. Mais si l'évolution se fait par à-coups violents (et les simulations ne l'excluent pas), les effets risquent d'être beaucoup plus inquiétants, quite à ce que se réalise ensuite le retour un nouvel équilibre".

Além do sumarizado no esquema (Figura 1) e da necessária importância a ser atribuída ao ritmo das mudanças climáticas, vale também citar os efeitos de ordem psicológica sobre indivíduos e grupos humanos, mais 
difíceis de mensurar, mas bastante previsíveis quando se consideram as profundas alterações no modo de vida, na migração forçada, no empobrecimento alimentar, na perda de bens materiais, etc. associados. Os efeitos tornam-se, assim, muito relativos sobre a população como um todo, pois a concentração da riqueza material e científico-intelectual numa pequena parcela da humanidade coloca a grande maioria dos homens, sobretudo na zona intertropical, numa flagrante condição de elevados risco e vulnerabilidade climáticas, como o considerou Confalonieri ao tratar de problemas específicos do Brasil (2003). A este respeito acrescenta-se também a concepção de Martens and McMichel (2001: 12).ao assinalarem que "human populations vary their vunerability to health hazards. A population's vulnerability is a function of the extent to wich a health outcome is sensitive to climate change and of the population's capacity to adapt to the new climate conditions. The vulnerability of a population depends on factors such as population density, level of economic development, food availability, local environmental conditions, preexisting health status, and the quality and availability of public health care".

Cenários futuros relacionados à intensificação do aquecimento planetário são construídos cada vez mais, e a partir deles uma gama considerável de especulações são elaboradas quanto à suas repercussões sobre a saúde humana. Ainda que a maioria das conjecturas apresente um futuro sombrio, cheio de problemas e de conflitos, parece necessário realçar o fato de que a atmosfera em particular, e a natureza como um todo, possuem dinâmicas próprias e em boa parte das vezes imprevisíveis. Na sua condição de movente (Monteiro, 1991) ela esta sempre apresentando novos desafios ao conhecimento, à previsão e à adaptabilidade humana à novas condições. Espera-se, de acordo com esta perspectiva, que a negatividade acenada para o futuro próximo possa ser revertida tanto por dinâmicas naturais menos impactantes quanto pela ação mais consciente e responsável da humanidade no que concerne à apropriação e uso dos bens e recursos naturais.

\section{Tropicalidade e saúde: Alguns aspectos atuais e cenários futuros.}

De acordo com o IPCC (2005) as mais profundas alterações da atmosfera planetária serão observadas nas latitudes médias e altas do planeta, destacando-se uma elevação térmica e pluviométrica máximas da ordem de $3^{\circ} \mathrm{C}$ a $12^{\circ} \mathrm{C}$ e de 0 a $0,50 \mathrm{~mm} /$ dia (cenários $\mathrm{A} 2$ e $\mathrm{B} 2$ ), respectivamente, no entorno do Pólo Ártico como a mais expressiva alteração climática global dos próximos 100 anos. As alterações previstas para a zona intertropical são menos expressivas, mas não menos preocupantes (arroladas que estão numa maior ocorrência de fenômenos extremos e impactantes associados a uma alteração genérica da paisagem como resposta a processos de ordem regional e global).

As baixas latitudes conjugam, geralmente, altas temperatura e umidade, embora apresentem também a conjugação entre altas temperaturas e ambientes secos (McGregor and Nieuwolt, 1998; Demangeot, 1999). A noção climática de trópico encerra esta condição, mas as áreas montanhosas distribuídas dentro desta zona não são abrangidas pela noção de clima tropical, pois nelas predomina o chamado clima de montanha, cujas características diferem-no daquele. Nesta faixa do planeta a previsão de intensificação do aquecimento é da ordem de $0^{\circ} \mathrm{C}$ a $4^{\circ} \mathrm{C}$ e $5^{\circ} \mathrm{C}$ (cenários $\mathrm{B} 2$ e $\mathrm{A} 2$, respectivamente) e a pluviosidade média apresentaria uma redução de 0 a 
$50 \mathrm{~mm} /$ dia (no entorno dos desertos do Sahara, Kalahari, Atacama e na Indochina e Caribe) concomitante a uma elevação média de 0 a $3 \mathrm{~mm} / \mathrm{dia}$ (com destaque sobre o centro do Oceano Pacifico) (IPCC, 2005).

A vida fisiológica em condições de clima tropical apresenta-se perfeitamente adaptada às características ambientais fortemente cambiáveis em espaços de tempo curto (sazonalidade climática), mas a ocorrência de fenômenos meteorológicos em escala temporal muito rápida (horária, diária e semanal) Ihe traz perturbações. O clima tropical, por suas características particulares, reúne excelentes condições para o desenvolvimento de um considerável numero de doenças, tanto ligadas ao excesso de calor quanto à queda abrupta do mesmo e à variabilidade termo-higro-pluviométrica. A entrada rápida de frentes frias de forte intensidade, por exemplo, engendra consideráveis impactos sobre os seres vivos e sobre a população humana desta área (Mendonça e Danni-Oliveira, 2005).

Neste sentido observa-se que boa parte das doenças tropicais são variáveis no tempo e no espaço, algumas são endêmicas (bilharziose, hepatite b, malaria, etc) outras são bastante imprevisíveis (dengue, peste, cólera, ebola, etc), o que dificulta consideravelmente a ação das políticas publicas para seu controle, fato que também está associado ao desrespeito às regras sanitárias elementares (Demangeot, 1999) por parte do estado e da população em geral.

Para este ultimo autor "as doenças especificamente tropicais, aquelas cuja ligação com o meio é clara, são doenças de carências, doenças parasitarias, doenças infecciosas (bacterianas ou virais), doenças micósicas". Nesta zona do planeta, continua o autor, "a não ser as secas, não existem catástrofes naturais tão graves quanto estas grandes doenças tropicais: nenhum sismo, nenhum ciclone não fazem, sem exceção, tantos mortos, estropiados e infelizes". De maneira mais direta ele faz referência ao Mal de Chagas (10 Milhões de pessoas vitimadas, principalmente na América Latina sobretudo no Brasil), à Doença do Sono (centenas de milhares de vitimas na África), à Bilharziose (200 000 mortes por ano) e à Malaria (1 a 2 milhões de mortos por ano, principalmente crianças) - (Demangeot, 1999: 297/298)

Germes, vetores e parasitas das doenças tropicais não conseguem viver e se reproduzir em outras condições ambientais, daí se falar que as doenças tropicais são naturais, pois somente ali é que se desenvolvem, numa interação natural perfeita. Estes microorganismos vivos dependem diretamente da temperatura, do fluxo das águas, dos tipos de culturas, das formas e da natureza dos telhados, das paredes, da vegetação natural, etc., enfim de um meio geográfico particular - o tropical, o que levou Max Sorre a criar o conceito de Complexo Patogênico (Demangeot, 1999: 299), como anteriormente citado. As atividades e construções humanas imprimem novas características nestes meios, anteriormente controlados pela dinâmica natural, como é o caso das grandes áreas agrícolas, dos grandes represamentos de águas e da urbanização caótica, o que favorece o desenvolvimento de muitas das doenças supramencionadas, derivando casos epidêmicos graves, ou introduzindo novas.

Contingências sócio-econômicas e políticas como a débil atuação do estado e dos governantes, a intensificação da pobreza e da miserabilidade humana, a deficiências das campanhas de saúde publica, a explosão da urbanização em cidades gigantescas e a formação de condições socioambientais de alta degradação concorrem para agudizar os problemas de saúde típicos da 
zona tropical. Observa-se assim, não somente a reincidência e emergência de doenças transmissíveis e parasitarias, mas também o desenvolvimento crescente das neoplasias, particularmente de doenças ligadas à obesidade e ao sedentarismo. A intensificação do aquecimento climático planetário coloca-se como mais um elemento a complicar a já complexa realidade desta zona do planeta. Isto é especialmente preocupante, pois observa-se uma forte tendência de expansão em altitude e em latitude das condições de tropicalidade, ou seja, estariam sendo criadas condições de expansão das doenças tropicais no mundo.

\section{Algumas doenças emergentes no contexto Brasileiro.}

A tropicalidade do Brasil é uma de suas principais características geográficas. Associada à extensão do território ela lhe garante uma infinidade de riquezas naturais, mas propicia, ao mesmo tempo e devido aos aspectos do seu clima, a formação de um ambiente favorável ao desenvolvimento de inúmeras doenças (Mendonça, 2001 e 2004). Assim, as condições de calor e umidade do ambiente brasileiro favorecem a atuação de determinados vetores, assim como de alguns veículos de transmissão, de várias doenças virais e bacterianas, das quais alguns exemplos são comentados a seguir.

Ao clima não se deve creditar toda a causa da incidência das doenças tropicais, mas não de se deve também menosprezar sua influência na manifestação das mesmas. Reiter (2001: 158), a respeito desta concepção e ao abordar algumas enfermidades tropicais como a malária, dengue e febre amarela, considera que "the recent ressurgence of many of diseases is a major cause for concern, but it is facile to attibute this resurgente to climate change. The principal determinants are politics, economics, and human activities. A creative and organized application of resources is urgently required to control these diseases regardless of future climate change".

Neste contexto, a influência do clima sobre algumas doenças reemergentes deve ser considerada. O melhor conhecimento do mesmo, e de sua participação na incidência de algumas delas, continua sendo, independentemente da intensificação do aquecimento ou do resfriamento climático global, um aspecto importante para o controle da transmissão e a prevenção das citadas doenças e de outras. No que concerne ao mundo tropical, e diante do ainda parcial conhecimento da dinâmica de sua atmosfera, muito há para se aprofundar no estudo do clima e de sua interação com os processos de saúde-doença da população.

No caso especifico da transmissão de doenças por mosquitos Reiter (2001: 142) considera que "the ecology, development, behavior, and survival of mosquitos and the transmission dynamics of the diseases they transmit are strongly influenced by climatic factors. Temperature rainfall, and humidity are especially important, but others, such as wind and the duration of daylight, can also be signifiant (...)". Esta constatação evidência tanto a importância das condições climáticas na incidência das doenças típicas do mundo tropical quanto revela a complexidade dos elementos e fatores do clima sobre as mesmas. Embora a temperatura do ar e a umidade sejam os dois componentes atmosféricos mais evocados nos estudos da interação entre o clima e as referidas enfermidades, outros elementos podem aparecer como determinantes 
em algumas delas. A analise detalhada do clima se coloca, então, como necessária ao estudo da geografia médica e da saúde nesta zona do planeta.

A malaria, doença endêmica do mundo tropical e que faz um considerável numero de vitimas a cada ano em muitos paises (cerca de 150 milhões de vitimas no mundo, $90 \%$ dos quais na África), principalmente no Brasil (450 a 600 mil casos registrados por ano), responde diretamente às condições climáticas desta parte do globo. Todavia, segundo Reiter (2004: 323) "a relação entre o clima e a transmissão da malaria é complexa e varia de acordo com o lugar (...)", o que reforça, por exemplo, a consideração da irregularidade temporo-espacial das doenças tropicais. De toda maneira, sabese da necessidade de condições de calor elevado e considerável umidade do ambiente para que ela se desenvolva, particularmente seu vetor, o mosquito do gênero Anopheles.

Trata-se de uma enfermidade recorrente no Brasil, particularmente na porção centro-norte, dominada por clima tropical úmido e equatorial associado à vegetação densa, e cujo controle apresenta consideráveis desafios à gestão da saúde no país. Considerando-se a intensificação do aquecimento climático regional e global associado à debilidade das políticas publicas de controle desta doença, especula-se que ela tenderá a ampliar seu espaço de incidência e elevará, substancialmente, o numero de vitimados; Reiter (2001) estima que haveria uma elevação de cerca de $60 \%$ de sua incidência nos trópicos. Os cinturões subtropicais atuais e o curso inferior das cadeias montanhosas circunvizinhas às áreas florestadas tropicais e subtropicais poderão apresentar forte intensificação desta doença no próximo século.

Dentre as doenças transmitidas por mosquitos a dengue configurase numa das mais importantes na atualidade (entre 50 e 100 milhões de casos registrados por ano), devido tanto à sua vasta distribuição pela região tropical do planeta quanto pelas várias e preocupantes epidemias registradas nas últimas décadas, das quais o numero de vitimados é consideravelmente elevado. Erradicada em meados da década de 1950, quando o governo brasileiro desenvolveu ampla campanha para controlar a febre amarela e cujo vetor é o mesmo (mosquito do gênero Aedes), ela retomou a cena epidemiológica do país em meados da década de 1980, momento a partir do qual sua incidência passou a ser cada vez mais preocupante.

Doença viral transmitida pelo mosquito Aedes aegypti, no Brasil (em outros paises também pelo Aedes albopictus), o controle da dengue constitui uma das principais preocupações da saúde pública no país. Não possuindo vacina para sua prevenção, e considerando-se o fato de que as condições tropicais são altamente favoráveis à ação do seu vetor, ela tem apresentado elevação número de casos bem como ampliação de sua área de ocorrência, o que pode estar ligado ao processo de intensificação do aquecimento estufa planetário.

Em estudos recentes sobre a interação entre a dengue $e$ as alterações climáticas na região Sul do Brasil, com ênfase no estado do Paraná, Mendonça et al (2003a e 2003b) registraram a elevação de cerca de $1,5^{\circ} \mathrm{C}$ na temperatura média regional associada a uma redução média anual das chuvas, o que ocorreu concomitantemente à elevação da incidência da doença na área. Os dados evidenciam intensificação do numero de casos da doença, particularmente no território paranaense (com forte evidência na área de 
domínio do clima Cfa), e também o registro de casos autóctones em locais que, até bem pouco, eram considerados indenes à sua manifestação, como o registrado na cidade de Curitiba no ano de 2002.

Paula (2005), em seu estudo acerca da correlação entre a incidência da dengue e as condições climáticas do estado do Paraná, evidenciou a formação de situações de risco e de expressiva vulnerabilidade da população à doença, sobretudo na porção norte-noroeste-oeste estadual e na situação de verão prolongado (dezembro a abril). Sendo um dos estados brasileiros onde a doença mais avançou na última década e no qual o número de casos autóctones tem sido bem mais importante que o de casos importados, os surtos epidêmicos ali foram muito importantes. Somente no ano de 2003 foram 12 mil casos notificados, sendo o mais elevado registro estadual daquele ano no contexto brasileiro e no qual registrou-se a ocorrência de vitimas fatais que desenvolveram o estágio hemorrágico da doença.

Nos estados de Santa Catarina e Rio Grande do Sul a incidência da doença é de caráter notadamente importado, sendo que os casos notificados são registrados geralmente na porção noroeste dos dois estados, e também na nordeste do primeiro. Todavia, o vetor da dengue é endêmico na região Sul do Brasil, assim como o é no norte da Argentina (Bejaran et al, 2003), fato que coloca esta vasta área numa condição de elevado risco à incidência de casos autóctones de dengue num cenário de intensificação do aquecimento climático global-regional.

A Leptospirose, cuja veiculação se faz pela água, é também uma doença que causa muitos problemas de saúde publica na população brasileira (5.576 casos em 1997, por exemplo, com letalidade média de 12,5\% - Guia Brasileiro de Vigilância Epidemiológica, 1998). Ela apresenta uma ligação muito direta com as condições climáticas, estando estreitamente relacionada à alta pluviosidade e ao calor. Sua manifestação, em grande parte do território nacional, reflete diretamente o ritmo sazonal do clima, sendo mais evidente na estação de verão e inicio do outono quando as águas veiculam a transmissão do vírus Leptospira nelas depositado através da urina de ratos.

Com o espraiamento das águas e a ocorrência de inundações durante e após os episódios pluviais, principalmente no verão prolongado, formam-se condições excelentes para a elevação do numero de casos de leptospirose na maior parte do território nacional. Ela apresenta também uma forte característica socioeconômica, pois é a população de baixa renda e habitante das periferias sociológicas e geográficas das grandes cidades a mais afetada. Nestes espaços o ambiente urbano é, em geral, bastante degradado, associando ausência de saneamento básico, acumulo de lixo a céu aberto e pobreza-miséria social. Ali os cuidados com o corpo e com o ambiente são deveras deficitários e, nos momentos de inundações, materiais degradados, animais e homens são envolvidos pela mesma água que se espraia, donde a transmissão da doença. Considerando-se que haveria uma elevação do nível das águas do mar decorrente da intensificação do aquecimento global, e também pelo fato de que boa parte das grandes áreas urbanizadas do Brasil situa-se na porção litorânea (Rio de Janeiro, Recife, Fortaleza, Salvador, Vitória, etc), especula-se que uma maior parcela da população estaria em condições de maior risco que no presente, pois as condições de vida tendem também a piorar (a pobreza e miséria têm piorado no país e no mundo!). 
Uma série de outras doenças bastante comuns no cenário brasileiro, pois que tropical, poderão apresentar intensificação de suas incidências num contexto de aquecimento global como o anunciado para o século que ora se inicia. A febre-amarela, a cólera, a meningite, a leishmaniose, dentre inúmeras outras poderão ser favorecidas num novo contexto climático. Mas, por outro lado, aquelas enfermidades típicas de condições ambientais de menor calor, como é o caso das rinites, pneumonias, bronquites, etc. poderão, ao contrário, apresentar tendência a reduzir-se. Enfim, quando se trata da construção de cenários, como se observa no quadro da ciência do presente, há que se considerar aspectos relacionados à previsibilidade e à aleatoriedade dos fenômenos da natureza, em de maneira especial quando se trata dos fenômenos atmosféricos e do clima.

\section{Síntese da discussão.}

Elemento de primeira importância no trato das questões ambientais, o clima exerce forte influência tanto sobre a paisagem físico-natural quanto sobre os homens e suas sociedades. Torna-se cada vez mais difícil questionar sua influência sobre as atividades humanas e a organização do espaço, mesmo que os avanços tecnológicos observados nos dois últimos séculos pareçam lhe fazer face em alguns aspectos particulares.

Historicamente, a evolução do planeta Terra e de suas diferentes e ricas paisagens foi marcada por formações atmosféricas e climáticas bastante distintas. No momento presente, sucessor de todo um processo de glaciações e no qual a média térmica do planeta gira em torno de $16,4^{\circ} \mathrm{C}$, acredita-se que esteja acontecendo a intensificação do aquecimento climático planetário. Ele tem sua gênese na própria dinâmica da natureza do planeta e estaria sendo acelerado como decorrência das atividades humanas, particularmente nestes últimos duzentos anos de industrialização. Os cenários criados em diversas partes do mundo, mesmo que registrando pensamento dissonante por alguns, anunciam uma elevação térmica entre $3^{\circ} \mathrm{C}$ e $6^{\circ} \mathrm{C}$, associados a uma diversificada alteração dos padrões pluviométricos atuais. Dentre os vários problemas decorrentes de uma tal mudança climática aqueles relativos aos impactos sobre a saúde humana aparecem como envoltos em grande preocupação internacional.

Mudanças climáticas de menor intensidade são especuladas para acontecerem na faixa intertropical do planeta quando comparadas às médias e altas latitudes, ou seja, ali ocorreria uma pequena intensificação das temperaturas associada à alteração da umidade (em alguns lugares a pluviosidade média se elevaria e reduzir-se-ia em outros, mas em quantidades muito pequenas). Várias enfermidades comuns ao mundo tropical encontrariam melhores condições para se proliferaram, ao mesmo tempo em que teriam seu espaço de incidência ampliado latitudinalmente e para localidades mais elevadas que no presente, pois que estas apresentariam condições climáticas mais aquecidas.

Algumas doenças chamadas de re-emergentes como a malária e a dengue, transmitidas por vetores, configuram desafios para a ação das políticas publicas, pois que as mudanças climáticas apresentam convincentes 
possibilidades para uma maior incidência das mesmas. No caso da segunda, alguns estudos já evidenciam sua ampliação para áreas no Sul do Brasil que têm apresentado tendências à intensificação do aquecimento, o que evidência uma clara relação entre sua expansão e a intensificação do efeito-estudo global na escala regional.

Tratar da expansão das doenças em condições climáticas alteradas num futuro próximo conduz diretamente à reflexão acerca das condições de desenvolvimento dos paises tropicais, na sua totalidade não desenvolvidos. 0 clima influencia muito mais diretamente àquela parcela da população que se encontra nas condições de miserabilidade e pobreza, pois que ela se encontra muito mais à mercê de sua influência que aquela pertencente à classe média e alta da sociedade. É sobre estes que os impactos se farão muito mais evidentes, e é dentre eles que as doenças farão mais vitimados.

Mas é ao Estado que a sociedade deve buscar para equacionar os problemas de ordem coletiva, pois se torna cada vez mais inadmissível aceitar o fato de o Brasil ser um dos mais ricos paises do mundo e não desenvolver campanhas de melhoria da educação, higiene e saúde da população, dentro do quê se inserem as políticas públicas de saúde. Com uma melhor atuação destas o número de vitimados será bem menor e a influência do clima sobre o bem estar da população será menos evidente.

Contudo, é preciso insistir, sem o aprofundamento das pesquisas e do conhecimento da atmosfera e do clima tropical, assim como das reais interações entre estes e a sociedade, ainda parcamente estudados, boa parte das argumentações ainda caminharão no campo das especulações, mesmo sobre a realidade do presente. Encontra-se, assim, em aberto, um frutuoso campo de investigação, trabalho e de atuação para a climatologia e para a geografia; o seu desenvolvimento promoverá avanços consideráveis para esta especificidade do conhecimento, mas é a sociedade como um todo que ganhará com as novas descobertas e propostas de melhoria da qualidade de vida.

\section{Referências bibliográficas}

BEJARAN, Rubens, GARIN, A. e SCHWEIGMANN, N. Aplicación de la predicción meteorological para el pronóstico de la abundancia potencial del Aedes aegypti en Buenos Aires. Revista Terra Livre, ano 19, vol.1, n. 20, jan/julho 2003, pp.171178.

BESANCENOT, Jean-Pierre. Le climat et la santé. In : DUBREUIL, Vincent et MARCHAND, Jean-Pierre (Organizadores). Le climat, léau et les hommes - Ouvrage en I'honneur de Jean Mounier. Rennes/France : Presses Universitaries de France, 1997. Pp. 87-104.

Colin, 1999.

Climat et santé. Paris: PUF, 2001. Paris: Armand

CLIFF, Andrew and HAGGETT, Peter. Disease implications of global change. In: JOHNSTON, R. J. et al. (Editors). Geographies of global change - Remapping the world in the late twentieth century. Oxford: Blakwel Publishers Ltd, 1995.

CONFALONIERI, Ulisses E. C. Variabilidade climática, vulnerabilidade social e saúde no Brasil. Revista Terra Livre, ano 19, vol.1, n. 20, jan/julho 2003, pp.193-204.

DEMANGEOT, Jean. Tropicalité - Géographie physique intertropicale. Paris: Armand Colin, 1999. 
GUIA BRASILEIRO DE VIGILÂNCIA EPIDEMIOLÓGICA, 5a Edição, Versão Ampliada, Brasília: Fundação Nacional de Saúde, 1998.

IPCC - International Panel on Climate Change. www.ipcc.ch

LAMARRE, Denis et PAGNEY, Pierre. Climats et sociétés. Paris: Armand Colin, 1999.

MARTENS, Pim and MCMICHEL, Anthony J. Environmental change, climate and health - Issues and research methods. London: Cambridge, 2002.

MCGREGOR, Glenn R. and NIEUWOLT, Simon. Tropical climatology. New York: John Wiley and Sons, 1998.

MENDONÇA, Francisco. Clima e criminalidade - Ensaio analítico da correlação entre a temperatura do ar e a incidência da criminalidade urbana. Curitiba: Editora da UFPR, 2001.

MENDONÇA, Francisco. Aquecimento global e saúde: Uma perspectiva geográfica- notas introdutórias. Revista Terra Livre, ano 19, vol.1, n. 20, jan/julho 2003, pp.205221.

MENDONÇA, Francisco. Rechauffement global et santé: Aspects généraux et quelques particularités du Monde Tropical. Annales de I'Association Internationale de Climatologie, Vol. 1, 2004, pp. 157-175.

MENDONÇA, Francisco e DANNI-OLIVEIRA, Inês Moresco. Climatologia - Noções básicas e aplicações brasileiras. Curitiba: Editora da UFPR, 2005, no prelo.

MENDONÇA, Francisco, KROKER, Rudolf e NOGAROLI, Mozart. Tendances climatiques et consequences regionales du rechauffement global dans I'etat du Parana/Brésil. Docukmentacja Geograficzna, n. 20, Polska Akademia Nauk - Warsovia/Polonia, 2003, pp. 241-244.

MENDONÇA, Francisco, PAULA, Eduardo V. e FERNANDES DE OLIVEIRA, Márcia M. $L$ 'incidence de la dengue dans le Parana et a Curitiba/Brésil - Approche climatologique de la periode 1995-2002. Docukmentacja Geograficzna, n. 20, Polska Akademia Nauk - Warsovia/Polonia, 2003, pp. 253-256.

MONTEIRO, Carlos Augusto de Figueiredo. Clima e excepcionalismo - Conjecturas sobre o desempenho da atmosfera como fenômeno geográfico. Florianópolis: Editora da UFSC, 1991.

PAULA, Eduardo V. Dengue: Uma análise climato-geográfica de sua manifestação no Estado do Paraná (1993-2003). Curitiba: UFPR, 2005. (Dissertação de Mestrado).

REITER, Paul. Global warming and malaria: A call for accuracy. The Lancet - Infectious Diseases. Vol. 4, June 2004, pp. 323-324. (Reflection \& Reaction). http: //infection.thelancet.com.

Climate change and mosquito-borne disease. Environmental health perspectives, vol. 109 [supplement 1], march 2001. pp.141-161.

SORRE, Maximilian. A Adaptação ao meio climático e biossocial - geografia psicologica. In: FERNANDES, Florestan (Coordenador). Max Sorre. São Paulo: Editora Atica, 1984. 